\title{
Evaluation of Multiple Intervention Effects on Marginal Hypertension in the Community Middle-aged and Elderly People
}

\author{
Xiaoyuan Xing ${ }^{1}$, Qing Zhao ${ }^{2}$ \\ ${ }^{1}$ Langfang Health Vocational College, Langfang, Hebei, 065001 \\ ${ }^{2}$ Beijing Shunyi Hospital, Beijing, 101300
}

Keywords: Borderline Hypertension; Multiple Interventions; Middle Aged and Elderly People

\begin{abstract}
Objective to investigate the effect of multiple interventions on the elderly with borderline hypertension. Methods By using a stratified random sampling, epidemiological survey of borderline hypertension and other chronic diseases of four community residents in Langfang City, through random measurement, a number of life intervention for 100 cases of hypertension in the middle-aged and elderly, a variety of interventions of dietary intervention for a period of 1 years of lifestyle intervention, such as health education, regular the physical examination, blood pressure changes were compared before and after intervention. Results After intervention, the change of residents' body mass index (BMI), dietary pattern, behavior habits, body mass index (BMI), waist circumference (WC), systolic blood pressure (SBP)and diastolic blood pressure (DBP) decreased are statistically significantly $(\mathrm{P}<0.05)$. After the intervention, the change of these indexes and the decrease of blood pressure was statistically significant $(\mathrm{P}<0.05)$. Conclusion It is a practical and effective way to control the borderline hypertension in community residents by changing the diet structure, the unhealthy behavior and life style, and carrying out health propaganda and education lectures.
\end{abstract}

\section{Introduction}

Twenty-first century, China is in a period of rapid economic development, people's living standards greatly improved, the dietary structure of our residents has undergone major changes, followed by the formation of many bad behavior and living habits, which gives a lot of chronic Non-communicable sexually transmitted diseases create favorable conditions in which only one of the high blood pressure is a serious threat to the lives and quality of life of our people. According to the recently completed "Chinese residents nutrition and chronic disease situation report (2015)" shows that in 2012 China's 18-year-old and above adults, the prevalence of hypertension was $25.2 \%$, while in 2002 this figure is still 18.8\%, we can see, China's prevalence of hypertension is on the rise, and hypertension is the basis of cardiovascular and cerebrovascular disease, cardiovascular and cerebrovascular disease mortality rate has leapt to the death of the top three diseases in China, we can not ignore the medical workers. Most of the high blood pressure is gradually formed, in order to explore the community in elderly patients with hypertension effective measures, I research group from the critical line of hypertension began to intervene, because the edge of hypertension is a prelude to persistent hypertension, Normal blood pressure and confirmed hypertension between the convertible type. Among the community residents, especially in the middle-aged population, the prevalence of marginalized hypertension is high and grows with age. Although the marginalized hypertension accounts for the proportion of the population, but because of no symptoms, easy to be ignored, and further development of persistent high blood pressure, chronic heart and cerebrovascular disease hidden risks, affecting the quality of life of patients. In order to prevent and reduce the occurrence and development of hypertension, my research team implemented a number of interventions on marginal hypertension the specific contents are as follows:

\section{Objects and Methods}

July 2015 to July 2016 selected four communities in Langfang City, the use of multi-stage stratified random sampling method to extract more than 45 years old resident 1340 as a baseline survey, 
medical examination and then on the basis of voluntary, fill in informed consent and finally to determine the subjects, 58 males and 42 females, included in the research team. (SBP) 18.7-19.9Kpa (140-149mmhg) or diastolic blood pressure (DBP) 12-12.5Kpa (90-94mmhg); secondly, the body mass index (BMI) is greater than or equal to 25; the last, All subjects had no cardiovascular disease. To ensure the accuracy of the results of the intervention, the study subjects were not allowed to take drugs that affected blood pressure and blood lipids throughout the intervention. 95 of them participated in the entire intervention process, accounting for $95 \%$ of the total sample.

Dietary intervention: the development of dietary principles and the preparation of recipes. According to the 2007 "Chinese Residents 'Dietary Guidelines" and the Chinese residents' balanced dietary pagoda, the dietary principles were designed and personal recipes were formulated. Will be a reasonable diet summarized as "two sentences, ten words", that is, "one two three four five, red, yellow, green and white", "one" refers to the daily generation of milk and yogurt; "two" refers to the daily intake of carbohydrates (Grain) 250-350 grams; "three" refers to the daily consumption of three high-quality protein food: 50 grams of lean meat, or eggs, or 100 grams of tofu, or 100 grams of chicken duck, or 100 grams of fish and shrimp; "Five" refers to the daily four grams of vegetables and fruits; "red" refers to the daily drink red wine 50 - "Black" refers to yellow vegetables; "green" refers to green tea and dark green vegetables; "white" refers to oatmeal or oatmeal; "black" refers to black fungus, 5-15 grams per day.

While emphasizing the importance of adequate drinking water and increased physical activity. Water is an important part of the diet, living in mild climatic conditions, light physical activity of adults daily drinking water at least $1200 \mathrm{ml}$ (about 6 cups). Physical exercise is closely related to health, adults should be accumulated every day is equivalent to not more than 6,000 physical activity.

Bad habits of intervention. For the elderly for bad life behavior mostly smoking, alcoholism; living habits of a number of lack of exercise. In July 2015, my staff members will enter the community to disseminate information on smoking and alcohol abuse to the residents of the participating materials. The publicity materials are also distributed in the community's promotional columns to encourage residents to stop smoking. Such as not more than 20g/d; female, alcohol intake of not more than $15 \mathrm{~g} / \mathrm{d}$ ); for the lack of physical exercise residents, my staff to promote residents to aerobic training or patience movement, choose their favorite and appropriate sports, Such as walking, qigong, tai chi, square dance, sooner or later, the intensity of exercise should be under the moderate strength of my own, to slightly tired is appropriate. Encourage the community residents to move in a step-by-step manner and persevere. The staff members were advised to go to the hospital for smoking, alcohol restriction and measurement by promoting blood pressure 1 week before, after 5 months and 10 months. Measure the blood pressure before the residents of the study at least 30 minutes off, continuous measurement 3 times, whichever is the average.

Health education. During the implementation of a number of interventions, my working group conducted a total of five health education and education lectures or counseling work, during which the main points to the community residents to carry out health education activities, including: (1) health education and health promotion agent The work and significance of community health care. Publicity to lectures and face-to-face consultation as the main form, in addition, also issued a propaganda materials and promotional materials, in the publicity of the newspaper also posted the contents of the mission, publicity and education. (2) 100 subjects who participated in my research group. In addition to mission and regular follow-up, they also taught them a "reasonable dietary formula" ("two-sentence, ten-word") and "prevention and treatment of hypertension 21 o'clock". Let the test people firmly believe that the edge of high blood pressure can be improved by improving the diet and reasonable exercise can be cured, so that the residents to promote each other help each other, to establish the confidence to overcome the disease. In the community to promote the dangers of obesity. Let community residents realize that "obesity" is a risk factor for many chronic diseases, such as hypertension, diabetes, hyperlipidemia and even some cancers are also closely related to obesity. So how to judge whether they are obese? Introducing how to calculate the body mass index 
(BMI) helps to determine the weight of the situation. BMI = body weight $(\mathrm{kg}) /$ height 2 ( $\mathrm{cm} 2)$, the normal range of 18.5-23.9, if higher than 25.0, then enter the category of overweight or obesity. Vigorously promote the whole body to maintain the benefits of the index to guide overweight how to lose weight. In the form of lectures to the community residents to introduce the four types of dietary structure, as well as the Chinese people the main types of dietary results, to introduce the advantages and disadvantages of each dietary structure, combined with today's actual situation, with reference to a healthy diet, to improve the residents of the meal Dish type. At the same time, for the masses who participated in our research group, the work of our staff members in the form of home visits not only guide the residents how to rationalize the dietary structure, but also guide the residents of the cooking methods. I am with the traditional cooking is: fried, fried, steamed, fried, stew, slip, boil, stew. Among them, frying, frying, frying, stewing, stewing and other cooking methods of large amount of edible oil, long-term use of these cooking methods of cooking dishes, will greatly reduce the amount of edible oil (less than or equal to $25 \mathrm{~g} / \mathrm{d}$ ), for the formation of hypertension Lay hidden. So we advocate residents eat less oil content of the dishes, eat more salad dishes. Cooking salt consumption is less than or equal to $6 \mathrm{~g} / \mathrm{d}$, in addition to encourage residents to eat less pickles, mostly healthy food.

Physical examination indicators. Monthly monitoring of blood pressure, body mass count asked about the health status.

Statistical analysis results are expressed as $\left(\mathrm{x}^{-} \pm \mathrm{s}\right)$ and percentage. The survey data will be entered into the computer, using SPSS10.0 statistical software package for statistical analysis, self-matching comparison, using their own paired t test.

\section{Results and analysis}

Table 1 Changes in the composition of major food structures before and after intervention (\%)

\begin{tabular}{llcccccc}
\hline Group & Livestock & birds & $\begin{array}{l}\text { Fish and } \\
\text { shrimp }\end{array}$ & $\begin{array}{l}\text { Soy } \\
\text { products }\end{array}$ & Eggs & $\begin{array}{l}\text { Coarse } \\
\text { grains }\end{array}$ & $\begin{array}{l}\text { Fruits and } \\
\text { vegetables }\end{array}$ \\
\hline $\begin{array}{l}\text { Before the } \\
\text { intervention }\end{array}$ & 14.69 & 7.54 & 3.21 & 6.75 & 6.72 & 3.84 & 57.34 \\
$\begin{array}{l}\text { After } \\
\text { intervention }\end{array}$ & 9.21 & 8.46 & 5.92 & 9.18 & 4.31 & 6.28 & 56.64 \\
\hline
\end{tabular}

\begin{tabular}{|c|c|c|c|}
\hline \multicolumn{4}{|c|}{ Table 2 Dietary changes before and after intervention $(\mathrm{g} / \mathrm{d})\left(\mathrm{x}^{-} \pm \mathrm{s}\right)$} \\
\hline Group & Before the intervention & After intervention & $\mathrm{p}$ \\
\hline Livestock & $143.58 \pm 28.13$ & $79.94 \pm 23.10$ & $<0.00$ \\
\hline birds & $41.85 \pm 14.14$ & $59.15 \pm 13.52$ & $<0.00$ \\
\hline $\begin{array}{l}\text { Fish and } \\
\text { shrimp }\end{array}$ & $32.42 \pm 9.45$ & $40.17 \pm 10.00$ & $<0.001$ \\
\hline Soy products & $55.19 \pm 23.42$ & $134.05 \pm 25.52$ & $<0.00$ \\
\hline Eggs & $45.28 \pm 18.27$ & $28.76 \pm 17.52$ & $<0.001$ \\
\hline Coarse grains & $20.47 \pm 11.34$ & $43.09 \pm 10.67$ & $<0.00$ \\
\hline $\begin{array}{l}\text { Fruits and } \\
\text { vegetables }\end{array}$ & $545.23 \pm 23.12$ & $540.71 \pm 20.12$ & $>0.05$ \\
\hline
\end{tabular}

As it can be seen from Table 1, after eating intervention, livestock and eggs intake has a more significant reduction; and poultry, fish and shrimp, soy products, coarse grain intake ratio increased by a different range.

As can be seen from Table 2: before and after dietary intervention by paired t test, the first six $\mathrm{P}$ values were $<0.001$, the results were significantly different. While the seventh, fruits and vegetables $\mathrm{P}$ value $>0.05$. Table 1 shows that after the meal intervention, community residents recognize that excessive intake of red meat, resulting in a fundamental change in dietary structure, which is the main reason for the gradual increase in hypertension, after repeated intervention to the intervention The end of the event, people's meal concept changes, greatly reducing the intake of red meat, and gradually increased the body of a little white meat (poultry) and fish and shrimp, these three kinds 
of meat changes in the dietary structure of meat The proportion and type of supply makes the dietary structure of the area beneficial. The eggs are also declining, and it is recognized that eggs (mainly eggs) contain higher levels of cholesterol, and that an egg contains cholesterol that is fully supplied by a healthy adult. Finally, the soybean and coarse grains have risen sharply, because the value of soy products gradually accepted by the residents, coupled with our intervention measures, so that this concept is more popular, so the changes in soy products there has been a very significant change The Then there is coarse grains, we can see that the effectiveness of our dietary fiber in the masses is also very effective, so the increase in coarse grains also increased accordingly.

Table 3 adverse behavior before and after the habit of intervention $\left(\mathrm{x}^{-} \pm \mathrm{s}\right)$

\begin{tabular}{|c|c|c|c|}
\hline Group & $\begin{array}{c}\text { Before } \\
\text { intervention }\end{array}$ & After the intervention & $\mathrm{p}$ \\
\hline $\begin{array}{c}\text { Quit } \\
\text { smoking } \\
\text { (piece/d) }\end{array}$ & $30.5 \pm 15.5$ & $7.5 \pm 5.5$ & $<0.00$ \\
\hline $\begin{array}{c}\text { Limit } \\
\text { wine }(\mathrm{g} / \mathrm{d})\end{array}$ & $33.45 \pm 20.14$ & $20.82 \pm 7.44$ & $<0.00$ \\
\hline $\begin{array}{r}\text { moveme } \\
\text { nt (steps/d) }\end{array}$ & $4000 \pm 1500$ & $5500 \pm 1200$ & $<0.00$ \\
\hline
\end{tabular}

There were 48 cases of smoking cessation community residents who participated in the bad habit of living habits. Among them, there were 46 males and 2 females, and 76 were community residents, including 53 males and 23 females. Residents of the research activities were involved in the campaign. As can be seen from Table 3 , the interventions were effective, $\mathrm{P}<0.00$, before and after the intervention of the indicators were statistically significant.

Table 4: Health education before and after BMI, blood lipids and blood pressure $\left(\mathrm{x}^{-} \pm \mathrm{s}\right)$

\begin{tabular}{|c|c|c|c|}
\hline Group & Before the intervention & After the intervention & $\mathrm{p}$ \\
\hline $\begin{array}{l}\text { Systolic blood } \\
\text { pressure }(\mathrm{mmHg})\end{array}$ & $124.8 \pm 19.4$ & $120.1 \pm 14.6$ & $<0.05$ \\
\hline $\begin{array}{l}\text { Systolic blood } \\
\text { pressure }(\mathrm{mmHg})\end{array}$ & $83.7 \pm 10.9$ & $79.3 \pm 8.2$ & $<0.05$ \\
\hline $\begin{array}{l}\underset{\text { Serum }}{(\mathrm{mmol} / \mathrm{L})} \text { cholesterol } \\
\end{array}$ & $5.9 \pm 1.0$ & $5.2 \pm 0.9$ & $<0.05$ \\
\hline $\begin{array}{l}\text { Serum triglycerides } \\
(\mathrm{mmol} / \mathrm{L})\end{array}$ & $1.8 \pm 0.9$ & $15 \pm 0.8$ & $<0.05$ \\
\hline $\begin{array}{l}\text { Body mass index } \\
(\mathrm{BMI})\end{array}$ & $24.5 \pm 2.7$ & $22.4 \pm 0.3$ & $<0.05$ \\
\hline
\end{tabular}

Through the four activities can be seen through the health publicity and education activities, its mission before and after the physical index, blood lipids and blood pressure have changed significantly, after finishing the observation indicators were significantly different, that is, $\mathrm{P}<0.05$.

\section{Discussion}

The occurrence of hypertension, development and genetic, poor behavior habits, the environment and other factors. At the same time unreasonable dietary structure, such as excessive intake of sodium salt, excessive intake of fat, alcohol, overweight or obesity is also an important risk factor for high blood pressure. In this study, after a few years of interventions in the past few years, the intervention object in the eating habits, dietary structure, behavioral lifestyle, nutrition knowledge and other aspects of a great change. It can be seen from Table 4 that this intervention has a significant therapeutic and controlled effect on marginal hypertension. If this study intervenes, it will avoid the emergence of a large number of hypertensive patients. The incidence of hypertension has decreased or disappeared, not only reduces the incidence of cardiovascular and cerebrovascular disease, mortality, but also conducive to other chronic and disease prevention and treatment. During 
the implementation of a number of interventions in our working group, we have the following experience: In order to make the object of intervention consistent, it is important to obtain the high unity of the object of knowledge in the "knowledge - attitude - behavior" "High unity" depends on community health education and health promotion. This is the people's "knowledge - letter - line" to improve the cornerstone, with this cornerstone, the other to consolidate the walk to be carried out smoothly, so after a series of our interventions, the community residents to improve the edge of hypertension-related Knowledge and complications of knowledge, an increase of life knowledge and health care knowledge, enhance self-care and awareness of disease prevention and treatment, while correcting the bad habits of life, the establishment of a scientific, reasonable and healthy way of life. After a number of interventions, many down to normal, which greatly proves that we have taken a number of interventions to control the community in the elderly marginalized hypertension is true and effective.

In summary, the implementation of a number of interventions in the community of elderly hypertrophy in the community is an effective way to reduce the number of hypertensive patients and improve the quality of life of the elderly in the community. This intervention only Good eating habits, lifestyle become part of the lifestyle, the case can really play a lasting role in the prevention and treatment of hypertension.

\section{Acknowledgements}

This article is 2016 Langfang Science and Technology Research and Development Program (the first batch) self-financing project.

Title: the study of dietary nutrition and health status in 45 years above in Langfang City.

The project number: 2016013043

\section{References}

[1] Xu Rongxian. Community care on the treatment of elderly hypertension [J]. Health must read, 2010, 11 (1): 49.

[2] Zhou Weiwei, Zhai Chengkai, Jiang Han, Jiang Mingxia. Evaluation of the Effect of Compound Nutrition Intervention on Hypertension in Middle and Old People in Community [J]. Journal of Nutrition and Health Promotion

[3] Mao Jun, Zhong Huasun, Kuang Xing Chi. Community nutrition intervention in elderly patients with critical hypertension in patients with blood pressure [J]. South China Nursing Journal, 2002, 9 (2): 67-68. 